\title{
AERODYNAMIC CHARACTERISITICS OF A MISSILE COMPONENTS
}

\author{
P.Sethunathan $^{1}$, A.Anupriya ${ }^{2}$, K.Hema Prabha ${ }^{3}$, T.S.Vaishnavi ${ }^{4}$ \\ ${ }^{1}$ Asst.Professor, Department of Aeronautical Engineering, Paavaai Group of Institutions, Namakkal \\ ${ }^{2}$ UG Students, Department of Aeronautical Engineering, Paavaai Group of Institutions, Namakkal \\ ${ }^{3} U G$ Students, Department of Aeronautical Engineering, Paavaai Group of Institutions, Namakkal \\ ${ }^{4} U G$ Students, Department of Aeronautical Engineering, Paavaai Group of Institutions, Namakkal
}

\begin{abstract}
A Missile is a self-propelled guided weapon system that travels through air or space. A powered, guided munitions that travels through the air or space is known as a missile (or guided missile). The Missile is defined as a space transversing unmanned vehicle that contains the means for controlling its flight path. The aerodynamic characteristics of a missile components such as body, wing and tail are calculated by using analytical methods to predict the drag and the normal forces of the missile. The total drag of the body is computed by using the parasite drag, wave drag, skin friction drag and base drag. The wing surface normal force coefficient $\left(C_{N}\right)_{\text {Wing }}$ is a function of Mach number, local angle of attack, aspect ratio, and the wing surface plan form area $\left(C_{N}\right)_{\text {Wing }}$, based on the missile reference area, decreases with increasing supersonic Mach number and increases with angle of attack and the wing surface area. When the wing surface area is reduced the total weight of the missile and drag are reduced thereby increasing the lift and achieve excessive stability.
\end{abstract}

Keywords-Aerodynamics, drag, missile, normal forces and stability

\section{INTRODUCTION}

Basically any object thrown at a target with the aim of hitting it is a missile. Thus, a stone thrown at a bird is a missile. The bird, by using its power of reasoning may evade the missile (the stone) by moving either to the Left, right, top or bottom with respect to the flight path (trajectory) of the missile. Thus, the missile in this case has been ineffective in its objective of hitting the bird (the target). Now, if the stone too is imparted with some intelligence and quick response to move with respect to the bird, to overcome aiming errors and the bird's evasive actions and hit it accurately, the stone now becomes a guided missile. The incorporation of energy source in a missile to provide the required force for its movement (propulsion), intelligence to go in the correct direction (guidance) and effective maneuvering (control) are mainly the technologies of guided missiles. They help in making a missile specific to a target, that is, they determine the size, range and state of motion of a missile. In a modern military usage, a missile, or guided missile, is a self -propellant guided weapon system, as opposed to unguided self-propelled munitions, referred to as just a rocket. Missiles have four system components: targeting and/or guidance, flight system, engine, and warhead. Missiles come in types adapted for different purposes: Surface to surface and air to surface missiles (ballistic, cruise, anti-ship, anti-tank, etc...), surface to air missiles (anti-aircraft and anti-ballistic), air to air missiles and anti-satellite missiles.

\section{LITERATURE SURVEY}

Missiles are generally classified on the basis of their Type, Launch Mode, Range, Propulsion, Warhead and Guidance systems.

\subsection{On the basis of Type}

\subsubsection{Cruise Missile}

A Cruise missile is an unmanned self-propelled (till the time of impact) guided vehicle that sustains flight through aerodynamic lift for most of its flight path and whose primary mission is to place an ordnance or special payload on a target. They fly within the earth's atmosphere and use jet engine technology. These vehicles vary greatly in their speed and ability to penetrate defences. Cruise missiles can be categorized by size, speed (subsonic or supersonic), range and whether launched from land, air, surface ship or submarine.

\subsection{On the basis of Launch mode}

Surface-to-surface Missile, Surface-to-Air Missile, Surface (coast)-to-sea Missile, Air-to-Air Missile, Air-to-Surface Missile, Sea-to-Sea Missile, Sea-to-Surface (coast) Missile, Anti-Tank Missile.

\subsection{On the basis of Range}

This type of classification is based on maximum range achieved by the missiles. The basic classification is as follows.

\subsubsection{Short range Missile}

A short range missile a ballistic missile of range $1,000 \mathrm{~km}$ or less. 


\subsubsection{Medium Range Missile}

A medium-range ballistic missile is defined by having a maximum range of between 1000 and $3000 \mathrm{~km}$. in modern terminology.

\subsubsection{Intermediate Range Ballistic Missile}

An intermediate range ballistic missile (IRBM) is a ballistic missile with a rage of $3000-5500 \mathrm{~km}$.

\subsubsection{Intercontinental Ballistic Missile}

An intercontinental ballistic missile (ICBM) is a ballistic missile with a minimum range of more than $5500 \mathrm{~km}(3400$ miles).

\subsection{On the basis of Propulsion}

Solid Propulsion, Liquid Propulsion, Hybrid Propulsion, Ramjet, Scramjet, Cryogenic.

\subsection{On the basis of Warhead}

\subsubsection{Conventional}

A Conventional warhead contains high energy explosive. It is filled with a chemical explosive and relies on the detonation of the explosive and the resulting metal casing fragmentation as kill mechanism.

\subsubsection{Strategic}

In a strategic warhead, radioactive materials are present and when triggered they exhibit huge radio activity that can wipe out even cities. They are generally designed for mass annihilation.

\subsection{On the basis of Guidance System}

Wire Guidance, Command Guidance, Terrain Comparison Guidance, Terrestrial Guidance, Inertial Guidance, Beam Rider Guidance ,Laser Guidance, RF and GPS Reference.

\section{AERODYNAMIC CHARACTERISTICS OF A}

\section{MISSILE}

The missile flies through the air it experiences aerodynamic forces and moments. These forces lift and drag may be classified into two general types:

1. Those due to air friction

2. Due to pressure

Before going into the discussion of the aerodynamic characteristics of the airframe components it may be well to show the resolution of these forces.

$$
\begin{aligned}
& \mathrm{D}=\mathrm{A} \cos \alpha+\mathrm{N} \sin \alpha \\
& \mathrm{L}=\mathrm{N} \cos \alpha-\mathrm{A} \sin \alpha \\
& \mathrm{A}=\mathrm{D} \cos \alpha-\mathrm{L} \sin \alpha
\end{aligned}
$$

$$
\mathbf{N}=\mathbf{L} \cos \alpha+\mathbf{D} \sin \alpha
$$

\subsection{Forebody}

The supersonic aerodynamic characteristics of a forebody will be discussed by passing the supersonic flow. The various fore body designs are given by Conical, Ogival, Hemispherical, and parabolic Forebody.

\subsection{Mid-section}

In most missile configurations, the mid-section is cylindrical in shape. This shape is advantageous from the stand point of drag, ease of manufacturing, and load carrying-capability. The zero-lift drag $\left(\alpha=0^{\circ}\right)$ of a cylindrical body is caused by viscous forces only (skin friction). At low angles of attack, a very small amount of normal force is developed on the body, and this results from the "carry-over" from the nose section. At rather large angles, some amount of normal force is developed because the cross-flow drag acts normal to the body centerline.

\subsection{Boattail}

The tapered portion of the aft section of the body is called the boattail. The purpose of the boattail is to decrease the drag of a body which has a "squared-off" base. The latter feature has relatively large base pressure and, consequently, high drag values because of the large base area. By "boattailing" the rear portion of the body, the base area is reduced and thus a decrease in base drag is realized. However, the decrease in base drag may be partially nullified by the boattail drag.

\subsection{Base pressure}

At supersonic velocities the base of the body experiences a large negative pressure (relative to ambient or free-stream static pressure) resulting in a substantial increase in missile drag. An accurate determination of these base-pressure coefficient is also quiet involved since it depends on many parameters, include boattail angle Mach number, and boattail length.

\section{DRAG PREDICTIONS ON MISSILE BODY}

The total drag is calculated for different mach numbers at various altitudes of $2000 \mathrm{~m}, 5000 \mathrm{~m}, 6096 \mathrm{~m}$, and $15000 \mathrm{~m}$. By comparing the tabulations it is concluded that the drag is reduced only when the Mach number is low at high altitudes. The given data are,

Nose fineness ratio, $1_{\mathrm{n}} / \mathrm{d}=3$

Nozzle exit area, $A_{e}=0.0 .0324 \mathrm{~m}^{2}$

Reference area, $S_{\text {ref }}=50.26 \mathrm{in}^{2}$

Length to diameter ratio, $1 / \mathrm{d}=18$

Reference area for wing, $S_{\mathrm{w}}=367 \mathrm{in}^{2}$

Reference area for wing, $\mathrm{S}_{\mathrm{T}}=1.54 \mathrm{ft}^{2}$

Wing leading edge sweep angle, $\wedge_{\mathrm{LE}}=45^{\circ}$

Wing leading edge section angle, $\delta_{\mathrm{LE}}=10.01^{\circ}$

Tail leading edge sweep angle, $\Lambda_{\mathrm{LE}}=57^{\circ}$

Tail leading edge section angle, $\delta_{\mathrm{LE}}=6.17^{\circ}$

Wing mean aerodynamic chord, $\mathrm{C}_{\mathrm{MAC}}=1.025 \mathrm{ft}$ 
Tail mean aerodynamic chord, $\mathrm{t}_{\mathrm{MAC}}=0.33$

At $20 \mathrm{Kft}(6096 \mathrm{~m})$, we calculate for various $1_{\mathrm{n}} / \mathrm{d}=0.5,1,1.5$, 2.4 and 3 . We conclude $1_{n} / d=3$ gives more reduction of drag. The tabulation and the graph for $\mathrm{l}_{\mathrm{n}} / \mathrm{d}=3$ is given below

Table 1: Drag at various Mach number

\begin{tabular}{|l|l|l|l|}
\hline $\begin{array}{l}\text { Mach } \\
\text { no }\end{array}$ & $\begin{array}{l}\text { Dynamic } \\
\text { pressure } \\
(\mathbf{N} / \mathbf{m})\end{array}$ & $\begin{array}{l}\text { Total } \\
\text { coefficient of } \\
\text { drag }\end{array}$ & $\begin{array}{l}\text { Drag } \\
(\mathbf{N})\end{array}$ \\
\hline 0.5 & 8138.779 & 0.2087 & 55.033 \\
\hline 0.9 & 26369.64 & 0.1757 & 150.1139 \\
\hline 1.1 & 39391.69 & 1.2684 & 1618.84 \\
\hline 1.5 & 73249.011 & 0.9552 & 2266.945 \\
\hline 2 & 130220.46 & 0.7477 & 3154.157 \\
\hline 2.5 & 203469.47 & 0.6385 & 4199.54 \\
\hline 3 & 292996.04 & 0.5373 & 5083.287 \\
\hline
\end{tabular}

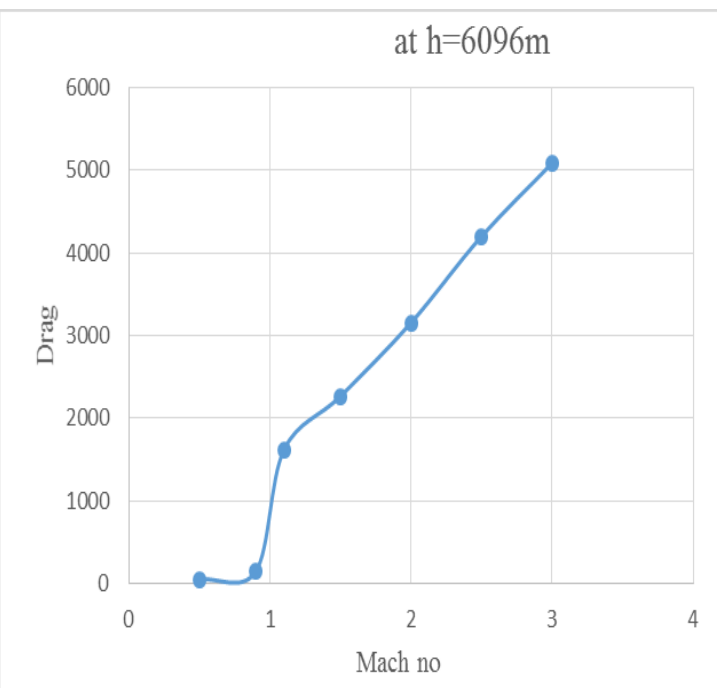

Graph 1: Mach number vs drag at an altitude of $6096 \mathrm{~m}$

At $6096 \mathrm{~m}, \mathrm{l}_{\mathrm{n}} / \mathrm{d}=3$ gives more reduction of drag. We took $1_{n} / d=3$ for various altitudes to measure the drag component, the various altitude considerations are $\mathrm{h}=2000 \mathrm{~m}, 5000 \mathrm{~m}$ and $15000 \mathrm{~m}$. By comparing different altitudes we got more than $65 \%$ reduction of drag at $15000 \mathrm{~m}$.

Table 2: Drag at various Mach number

\begin{tabular}{|l|l|l|l|}
\hline Mach no & $\begin{array}{l}\text { Dynamic } \\
\text { pressure } \\
\text { (N/m) }\end{array}$ & $\begin{array}{l}\text { Total } \\
\text { coefficient } \\
\text { of drag }\end{array}$ & $\begin{array}{l}\text { Drag } \\
(\mathbf{N})\end{array}$ \\
\hline 0.5 & 2119.08 & 0.2778 & 18.90 \\
\hline 0.9 & 6865.84 & 0.2301 & 51.142 \\
\hline 1.1 & 10256.392 & 1.3661 & 451.46 \\
\hline 1.5 & 19071.804 & 1.1195 & 689.16 \\
\hline 2 & 33905.43 & 0.9259 & 1016.97 \\
\hline 2.5 & 52977.234 & 0.7961 & 1364.48 \\
\hline 3 & 76287.21 & 0.702 & 1733.15 \\
\hline
\end{tabular}

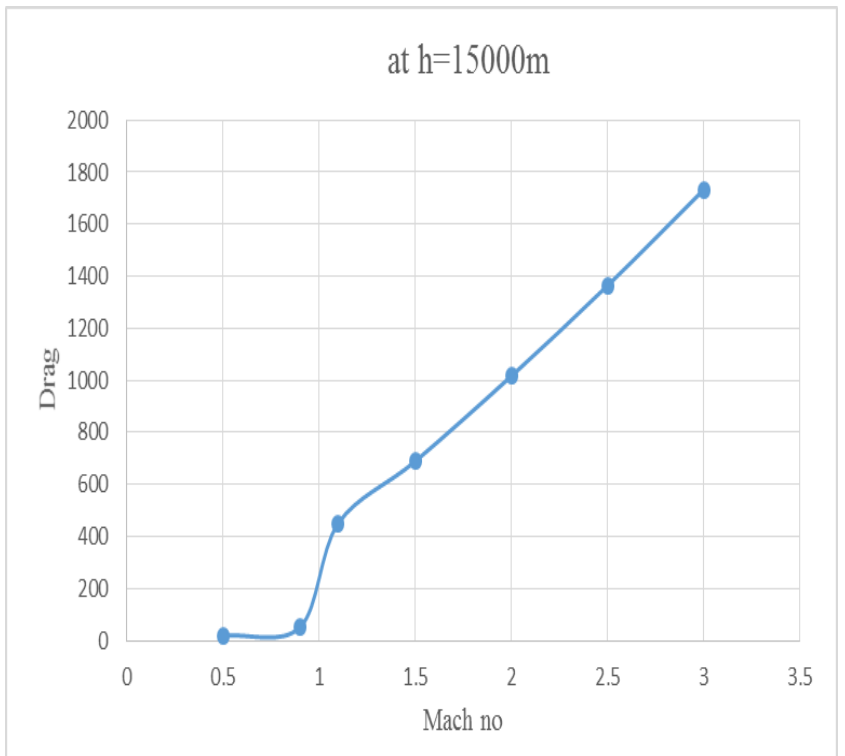

Graph 2: Mach number vs. drag at nose fineness ratio 3

\section{NORMAL FORCE}

\subsection{Normal Forces at different Angle of Attack (Movable Wing)}

The rocket baseline missile wing is limited to a maximum angle of attack of 22 degree due to stall of the wing. This results in a maximum angle of attack of 9.4 degree due to stall of the wing. This results in a maximum angle of attack of 9.4 degree for a maximum wing control deflection of 12.6 deg. For this condition, the normal force coefficient of the wing, based on wing area, is equal to 1.08. The normal force coefficient of the wig, based on the body reference crosssectional area, is equal to 7.91. Because the rocket baseline missile has a larger wing, most of the normal force for the missile comes from the wing

Table 3: Normal force at an angle of attack $22^{\circ}$

\begin{tabular}{|l|l|l|}
\hline \multicolumn{1}{|c|}{$\begin{array}{l}\text { Mach } \\
\text { no }\end{array}$} & $\begin{array}{l}\mathbf{M}<\left\{\mathbf{1}+[\mathbf{8} /(\boldsymbol{\pi} \mathbf{A})]^{\mathbf{2}}\right\}^{\mathbf{1 / 2}} \\
\mathbf{M}<\left\{\mathbf{1}+[\mathbf{8} /(\boldsymbol{\pi} \mathbf{A})]^{\mathbf{2}}\right\}^{\mathbf{1} \mathbf{2}}\end{array}$ & $\left(\mathbf{C}_{\boldsymbol{N}}\right)$ \\
\hline 0.5 & $0.5<1.347$ & 17.7003 \\
\hline 0.9 & $0.9<1.347$ & 17.7003 \\
\hline 1.1 & $1.1<1.347$ & 17.7003 \\
\hline 1.5 & $1.5>1.347$ & 15.1894 \\
\hline 2 & $2>1.347$ & 11.0694 \\
\hline 2.5 & $2.5>1.347$ & 9.2383 \\
\hline 3 & $3>1.347$ & 8.1613 \\
\hline
\end{tabular}




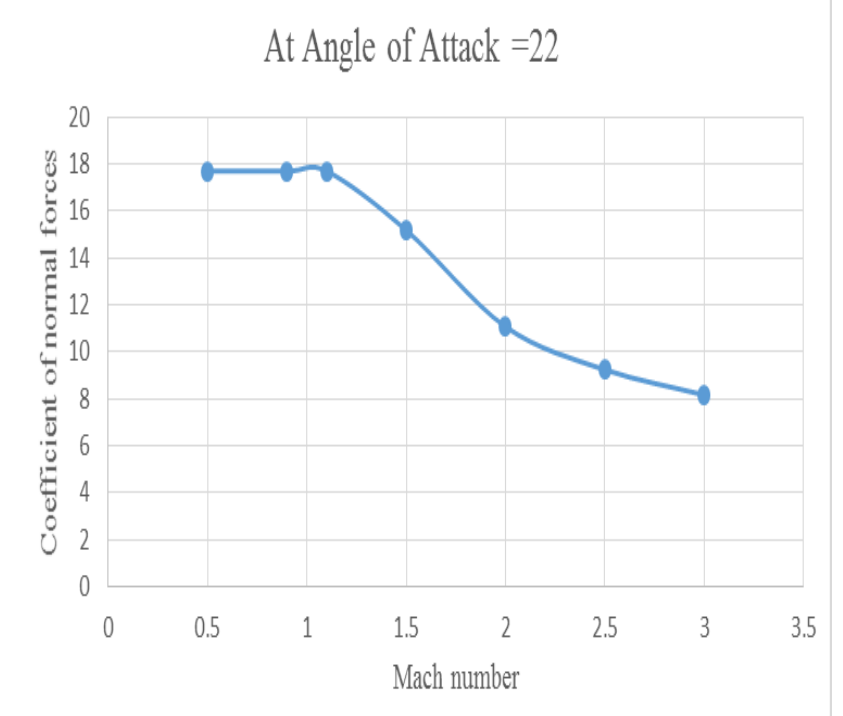

Graph 3: Mach number vs. coefficient of normal forces at an angle of attack $22^{\circ}$

A typical missile requires aspect ratio, wing planform area and reference area for finding the normal force of the wing, the tail and the body. The performance of the normal force increases with decreasing the Mach number at an angle of attack 22 degree. This can be clearly visualized from the tabulation and graph which is calculated from the data given earlier in this chapter

\subsection{Normal Forces at different Angle of Attack (Fixed Wing)}

The prediction of normal force for fixed wing at different angle of attack is used to determine the performance of a missile. For achieving the stability of the missile angle of attack is changed at different mach numbers. While comparing $1^{\circ}, 5^{\circ}, 10^{\circ}$ and $20^{\circ}$ angle of attack, we can conclude $20^{\circ}$ gives maximum normal force $\left(c_{N}\right)$.

Table 4: Normal force at an angle of attack $20^{\circ}$

\begin{tabular}{|l|l|l|}
\hline $\begin{array}{l}\text { Mach } \\
\text { no }\end{array}$ & $\begin{array}{l}\mathbf{M}<\left\{\mathbf{1}+[\mathbf{8} /(\boldsymbol{\pi A})]^{\mathbf{2}}\right\}^{\mathbf{1 / 2}} \\
\mathbf{M}<\left\{\mathbf{1}+[\mathbf{8} /(\boldsymbol{\pi} \mathbf{A})]^{2}\right\}^{\mathbf{1 / 2}}\end{array}$ & $\left(\mathbf{C}_{\boldsymbol{N}}\right)$ \\
\hline 0.5 & $0.5<1.347$ & 24.2685 \\
\hline 0.9 & $0.9<1.347$ & 24.2685 \\
\hline 1.1 & $1.1<1.347$ & 24.2685 \\
\hline 1.5 & $1.5>1.347$ & 21.0599 \\
\hline 2 & $2>1.347$ & 16.2831 \\
\hline 2.5 & $2.5>1.347$ & 14.1596 \\
\hline 3 & $3>1.347$ & 12.9068 \\
\hline
\end{tabular}

For fixed wing, the stability is achieved at lower normal force when the angle of attack and the Mach number is maximum

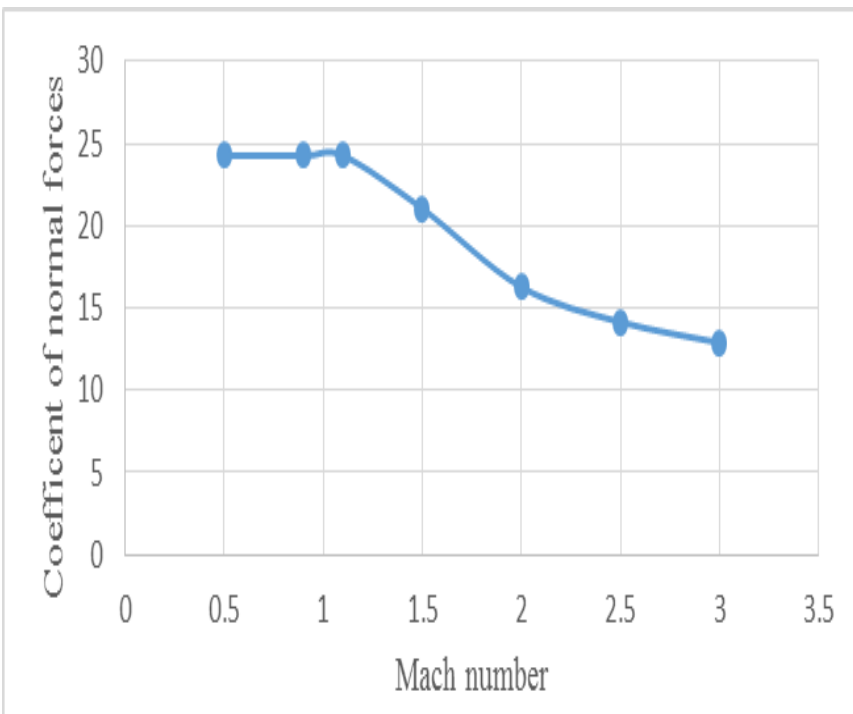

Graph 4: Mach number vs. coefficient of normal forces at an angle of attack $20^{\circ}$

\section{STABILITY OF MISSILE COMPONENTS}

An important concept that must be considered when designing an aircraft, missile, or other type of vehicle, is that of stability and control. The study of stability is related to the flying qualities of the vehicle and gives us some indication if the vehicle will be easy, difficult, or impossible to fly. The control aspect of the study will indicate if the control surfaces are large enough to force the vehicle into the desired flight manoeuvers.

Hence we can calculate, if necessary, the mean aerodynamic chord for any wing using the following relation:

$$
\bar{C}=\frac{2}{s} \int_{0}^{\frac{b}{2}}\left[c(y)^{2}\right] d y
$$

This concludes the basic concepts section.

The rocket baseline is based on analytical prediction of aerodynamics which follows the given data

Length of the missile $1=144$ in

Wing surface area $S_{\mathrm{w}}=2.55 \mathrm{ft}^{2}$

Reference area $S_{\text {Ref }}=0.349 \mathrm{ft}^{2}$

Aspect ratio $\mathrm{A}_{\mathrm{w}}=2.82$

Mean aerodynamic chord $\left(\mathrm{C}_{\mathrm{MAC}}\right)=13.3$ in

Mean aerodynamic centre $\left(\mathrm{X}_{\mathrm{MAc}}\right)=67.0$ in from nose tip

Mach number $\mathrm{M}=3$

Diameter $d=8$ in

$$
\left(X_{C G}\right)=1 / 2
$$

$=144 / 2=72 \mathrm{in}$

$\left(X_{C P}\right)_{\mathbf{B}} \approx d$

$=8$ 
$\left(X_{C P}\right)_{\mathrm{T}} \approx \mathbf{I}-\mathrm{d}$

$=144-8=136$

$\left(C_{N_{X}}\right)_{B}=2$ per radian

$\left(\mathrm{C}_{N_{\mathrm{x}}}\right)_{\mathrm{T}}=\left(\mathrm{C}_{N_{\mathrm{x}}}\right)_{\mathrm{W}}$

$=4 /\left(M^{2}-1\right)^{1 / 2}$

$=4 /\left(3^{2}-1\right)^{1 / 2}=1.4142$

$\left(\mathrm{C}_{N_{\mathrm{X}}}\right)_{\mathrm{T}}=\left(\mathrm{C}_{N_{\mathrm{X}}}\right)_{\mathrm{W}}=1.4142$

$\left(X_{C P} / C_{M A C}\right)_{\mathrm{W}}=\left[\mathrm{A}_{\mathrm{W}}\left(\mathrm{M}^{2}-1\right)^{1 / 2}-0.67\right] /\left[2 \mathrm{~A}_{\mathrm{W}}\left(\mathrm{M}^{2}-1\right)^{1 / 2}-1\right]$

$=\left[2.82\left(3^{2}-1\right)^{1 / 2}-0.67\right] /\left[2 * 2.82\left(3^{2}-1\right)^{1 / 2}-1\right] \quad\left(\boldsymbol{X}_{C P} /\right.$

$\left.C_{\text {MAC }}\right)_{\mathrm{W}}=\mathbf{0 . 4 8 8 6}$



$=0.4886 * 13.3$

$=6.5$ in from leading edge of MAC

$\left(X_{C P}\right)_{\mathrm{w}}=6.5+67.0$

\section{$=73.5$ in from nose}

$\mathbf{S}_{\mathrm{T}} / \mathbf{S}_{\mathrm{Ref}}=\left(\mathbf{C}_{\mathrm{N} \omega}\right)_{\mathrm{B}}\left[\mathbf{X}_{\mathrm{CG}}-\left(\mathbf{X}_{\mathrm{CP}}\right)_{\mathrm{B}}\right] / \mathbf{d}+\left(\mathbf{C}_{\mathrm{N} \alpha}\right)_{\mathrm{W}}\left[\mathbf{X}_{\mathrm{CG}}-\left(\mathbf{X}_{\mathrm{CP}}\right)_{\mathrm{W}}\right] / \mathbf{d}$ $\left(\mathbf{S}_{\mathrm{W}} / \mathbf{S}_{\mathbf{R e f}}\right) /\left(\mathbf{X}_{\mathbf{C P}}\right)_{\mathrm{T}}-\left(\mathbf{X}_{\mathbf{C G}}\right) / \mathbf{d}\left(\mathbf{C}_{\mathrm{N} \mathbf{N}}\right)_{\mathrm{T}}$

$=2(76.2-8) / 8+1.414(76.2-73.5) / 8(2.55 / 0.349) /(136-$

76.2/8) (1.414)

$=17.05+0.477 *(7.306) / 10.56=\mathbf{1 . 6 9}$

$\left(\mathbf{S}_{\mathbf{T}}\right)_{\text {Ref }}=1.69 * 0.349=\mathbf{0 . 5}$

\section{CONCLUSION}

From, this report we have conclude that the drag performance is varied by changing the Mach number with altitude and nose fineness ratio. The drag is reduced when an altitude increases with low Mach number and the stability of a missile can be achieved when a normal force is minimum. These results are obtained from the calculated values of drag with various altitudes and nose fineness ratio of the wing, the tail and the body of the missile. For the further development of this type of missile, by reducing the size of a tail area the stability of a missile can be easily achieved. At low diameter of missile, the drag can be easily reduced.

\section{REFERENCES}

[1]. Zona, R., "Aerodynamic Predictions, Comparisons, and Validations Us- ing Missile DATCOM," Technology Service Corp., W233-001/rlz, Silver Spring, MD, Sept. 2001.

[2]. Chapra,S.C., Numerical Methods for Engineers,3rded.,McGraw-Hill, New York, 1998, pp. 425, 426

[3]. Jorgensen, L.H., "Prediction of Aerodynamic Characteristics for Slender Bodies Alone and Width Lifting Surfaces to High Angles of Attack," AGARD-CP-247, 1978.

[4]. Busemann, A.: Aerodynamic Lift at Supersonic Speeds, lecture given at the 5th Volta. Conference at Rome, published in Luftfahrt-For8ch., vol. 12, no. 6, 1935 (British ARC Rep. 2844, Feb. 3, 1937).
[5]. Krzywoblocki, M. Z.: Aerodynamic Studies: The Forces Acting on an Air Vehicle-A Review of the Literature, W ADO Tech. Note 56-360, pt. XVI, May, 1957 (ASTIA AD 130862).

[6]. Jones, R. T.: Theory of Wing-body Drag at Supersonic Speeds. NAOA Research Mem. A53HISa, 1953.

[7]. Pitts, W. C., J. N. Nielsen, and G. E. Kaattari: Lift and Center of Pressure of Wing-body-tail Combinations at Subsonic, Transonic, and Super- sonic Speeds, NAOA Tech. Repe. 1307, 1957 